\title{
Grave Mathematical Errors in a Behavior Analysis Textbook
}

\section{Makoto Yamaguchi}

Department of Educational Psychology, Waseda University, Shinjuku, Tokyo 169-8050, Japan

Behavior Analysis and Learning [1] has been read and taught in university classes throughout the world for many years. Particularly, its sincere attempts to explain difficult concepts plainly made it one of the most popular textbooks in the field, and it underwent several revisions.

Unfortunately, with regard to mathematical parts, it contains numerous grave errors, which must have led some researchers to be reluctant to recommend it to their students. Also, numerous students may have been confused by the textbook over many years. In this brief note, I correct such errors and hope this helps its authors to improve that renowned textbook. Here its third edition (2004) is critiqued and many issues are raised, only one of which has been corrected in the newest edition.

On p.71, the Rescorla-Wagner equation is explained. Besides the fact that the equation is expressed in unconventional notations, it is plainly wrong. The equation should read:

$\Delta \mathrm{V}=\mathrm{S}\left(\mathrm{V}_{\max }-\mathrm{V}-\mathrm{V}_{\text {sum }}\right)$

as in the fifth edition. Although this form of equation is not used in the literature, given the definitions used in this book, this is not wrong. However, in notations usually used in the literature, $\mathrm{V}$ is included in $\mathrm{V}_{\text {sum }}$. Therefore, the following conventional form should be preferred:

$\Delta \mathrm{V}=\mathrm{S}\left(\mathrm{V}_{\max }-\mathrm{V}_{\text {sum }}\right)$

On p.247, matching law is converted from proportional form to ratio form. Although this is not wrong (apart from clear typos in the second line), more elegant conversion should be preferred. Consider the following proportional relation:

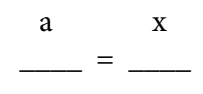

$\mathrm{a}+\mathrm{b} \quad \mathrm{x}+\mathrm{y}$

One can divide each side by the numerator in that side, and the result is:

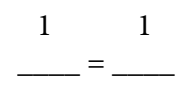

$1+\mathrm{a} / \mathrm{b} \quad 1+\mathrm{y} / \mathrm{x}$

Therefore, with only slight further arranging, one can obtain the ratio form. Notice that this process did not invovle combining variables in both sides of the equation, unlike the process shown in the textbook.

On p.249, linear functions are explained as an "advanced" issue, but students must not write functions that way. A mathematical function:

$y=f(x)$

means "y is a function of $\mathrm{x}$ ", not "y equal $\mathrm{f}$ times $\mathrm{x}$ ". Therefore, one should write (for instance):

\section{Publication History:}

Received: September 16, 2016

Accepted: October 19, 2016

Published: October 21, 2016

\section{Keywords:}

Behavior analysis, Grave mathematical errors

\section{$\mathrm{y}=\mathrm{nx}+\mathrm{m}$}

There are various accepted ways to write a function, so many other variations are possible, However, the one in the textbook is unacceptable.

On p.347, mathematical sets are written, which may be one of the most grave errors remaining uncorrected in the newest edition. Sets and elements are confused throughout the text, so the authors' explanations do not make sense. As " \{\} " should be used to denote sets, students must not use "\{\}" to denote elements in the sets. Also commas are used wrongly. Therefore, for instance,

\section{$\{\mathrm{X}\},\{\mathrm{X}, \mathrm{X}\},\{\mathrm{X}, \mathrm{X}, \mathrm{X}\}$}

in the textbook must read:

\section{$\mathrm{X}, \mathrm{XX}, \mathrm{XXX}$}

and so on.

The author hopes this note contributes to improving the important textbook in the future editions, as well as informing confused students who read it.

\section{Rerefences}

1. Pierce WD, Cheney CD (2013) Behavior analysis and learning (5th ed.). New York, NY: Psychology Press. 